Hsu, P. Y., Aurisicchio, M., and Angeloudis, P. (2017). "Supply Chain Design For Modular Construction Projects.” In: LC3 2017 Volume II - Proceedings of the 25th Annual Conference of the International Group for Lean Construction (IGLC), Walsh, K., Sacks, R., Brilakis, I. (eds.), Heraklion, Greece, pp. 797-804. DOI: https://doi.org/10.24928/2017/0193

\title{
SUPPLY CHAIN DESIGN FOR MODULAR CONSTRUCTION PROJECTS
}

\author{
Pei-Yuan $\mathrm{Hsu}^{1}$, Marco Aurisicchio ${ }^{2}$, and Panagiotis Angeloudis ${ }^{3}$
}

\begin{abstract}
The construction sector is currently undergoing a shift from stick-built construction techniques to modular building systems. If construction supply chains are to support this transformation, they need to be modified and strengthened using an adapted logistics system. The aim of this study is to establish a mathematical model for the logistics of modular construction covering the three common tiers of operations: manufacturing, storage and construction. Previous studies have indicated that construction site delays constitute the largest cause of schedule deviations. Using the model outlined in this paper we seek to determine how factory manufacturing and inventory management should be adapted to variations in demand on the construction site. We propose a Mixed Integer Linear Programming model that captures construction scenarios with demands for modular products that are either foreseeable or abruptly disrupted. The use of the model is illustrated through a case study of bathroom pods for a building project. The model outputs include supply chain configurations that reduce total costs across a range of scenarios. The model could serve as a decision support tool for modular construction logistics.
\end{abstract}

Keywords: Logistics, modular construction, inventory, supply chain, mixed integer programming

\section{INTRODUCTION}

Building materials in modular construction projects are initially transported to manufacturing facilities where they are transformed into modular products (Rogers and Bottaci 1997). This process is absent in traditional construction projects (Lawson et al. 2014). Furthermore, these modular products are often large in size. Thus for construction sites with limited storage space, warehouses are needed to temporarily stock products (Azhar et al. 2013; Li et al. 2014). In these contexts, the structure of the construction supply chain is altered, because it now possesses the characteristic of both construction and manufacturing.

The logistics of modular construction also includes aspects that distinguish it from generic supply chains (De La Torre, 1994). For example, modular products such as bathroom and kitchen pods often are tailor-made and project-specific. Hence, they normally cannot be procured from other manufacturers when the production fails to meet the demand. Also, the quantity of modular products produced should match the demand from the construction sites, and consequently, the inventory will reach zero when a project ends. Furthermore, additional assembly processes and costs are required after the products are delivered to final customers (construction sites). Therefore, previous studies on

1 PhD Student, Dyson School of Design Engineering, Imperial College London, UK, p.hsu15@imperial.ac.uk

Senior Lecturer, Dyson School of Design Engineering, Imperial College London, UK, m.aurisicchio@imperial.ac.uk

3 Senior Lecturer, Department of Civil and Environment Engineering, Imperial College London, UK, p.angeloudis@imperial.ac.uk 
integrated supply chains can only partially inform a new logistic model for modular construction as additional features have to be considered.

A key issue in a three-tier modular construction logistics - including a manufacturing factory, a storage facility, and construction sites - is understanding how to integrate the various elements of the supply chain seamlessly. The aim of this research is to develop a mathematical model to specify optimal configurations for the logistics of modular construction, and determine the best manufacturing rate, schedule and initial inventory level for multi-products needed on multi-construction sites under various demand profiles, so that the demand can be fulfilled at the lowest cost. Under this circumstance, the logistic system can remain competitive by operating at the lowest cost with minimal waste, in alignment with the goal of lean construction.

\section{BACKGROUND}

\section{Supply chain integration}

Supply chains are commonly modelled as dynamic systems involving multiple parties (Akkermanns et al. 1999). Chandra and Fisher (1994) pointed out that in supply chain design, the activities in different tiers should be considered simultaneously to achieve high efficiency. Coelho and Laporte (2014) also suggested that decisions in production, shipment and inventory should be modelled in a single problem statement. Under this context, a single model and its solutions can serve as the foundation for tactical decision making in complex supply chain design (Adulyasak et al. 2014).

A recent review of research on integrated supply chain design by Díaz-Madroñero et al. (2015) found that a common assumption adopted by previous researchers is that the customers' demand must be satisfied at all time. Another finding in this review paper is that most of the integrated supply chain design problems studied were modelled using mixed integer linear programming (MILP), and the total operational cost of the supply chain was always set as the objective function in the model.

As with previous studies, the design of a multi-tier supply chain in modular construction can also be modelled by MILP. However, it should reflect its features that set it apart from conventional construction and generic logistics operations.

\section{Fluctuation in the demand for modular construction products}

In modern construction projects, many factors can cause schedule deviations. Gündüz et al. (2013) listed 83 distinct factors causing delays in building projects. Of these-over $90 \%$ are traced to activities within construction sites. When delays occur, progress lags behind the planned schedule and the demand for materials on sites becomes lower, which in turn would make an impact on the upstream logistics (Sweis et al. 2008). Since delays in construction schedules are almost inevitable (Sambasivan and Soon 2007), and changes in the demand often have a severe impact on the upstream logistics, their cause-effect relationship deserves special attention (Assaf and Al-Hejji 2006).

Although certain demand variations are foreseeable, some may happen unexpectedly. Illustrating these demand fluctuations in a mathematical model and identifying the optimal solution which can effectively mitigate the extra cost are problems that have to be addressed when building a logistic system for modular construction. 


\section{METHODOLOGY}

\section{Assumptions}

The assumptions used in the model to represent logistics operations in modular construction projects are outlined. The factories are assumed to be able to manufacture several types of modular products simultaneously. Manufactured items are transported to warehouses, given component sizes and inventory holding restrictions. Additional costs are incurred when production rates are boosted.

Since most modular products are tailor-made with exact numbers being produced based on specific design requirements, product inventories are expected to be exhausted by the end of the project. On the demand side, modular products are transported from the warehouse to construction sites according to the daily demand for each product at each location on a just-in-time basis. It is noted that demands at each site must be met.

The model anticipates that delays may occur during construction. The case study presented later in this paper focuses on the lags triggered by foreseeable causes such as weather or abrupt disruptions.

\section{The model}

The objective of the model is to minimise the overall operational cost of the supply chain, which includes the costs of production, transportation, inventory and assembly. As such, the model seeks to determine optimal daily production rates and initial inventory amounts that can deliver the lowest overall operational cost. The following notation is used:

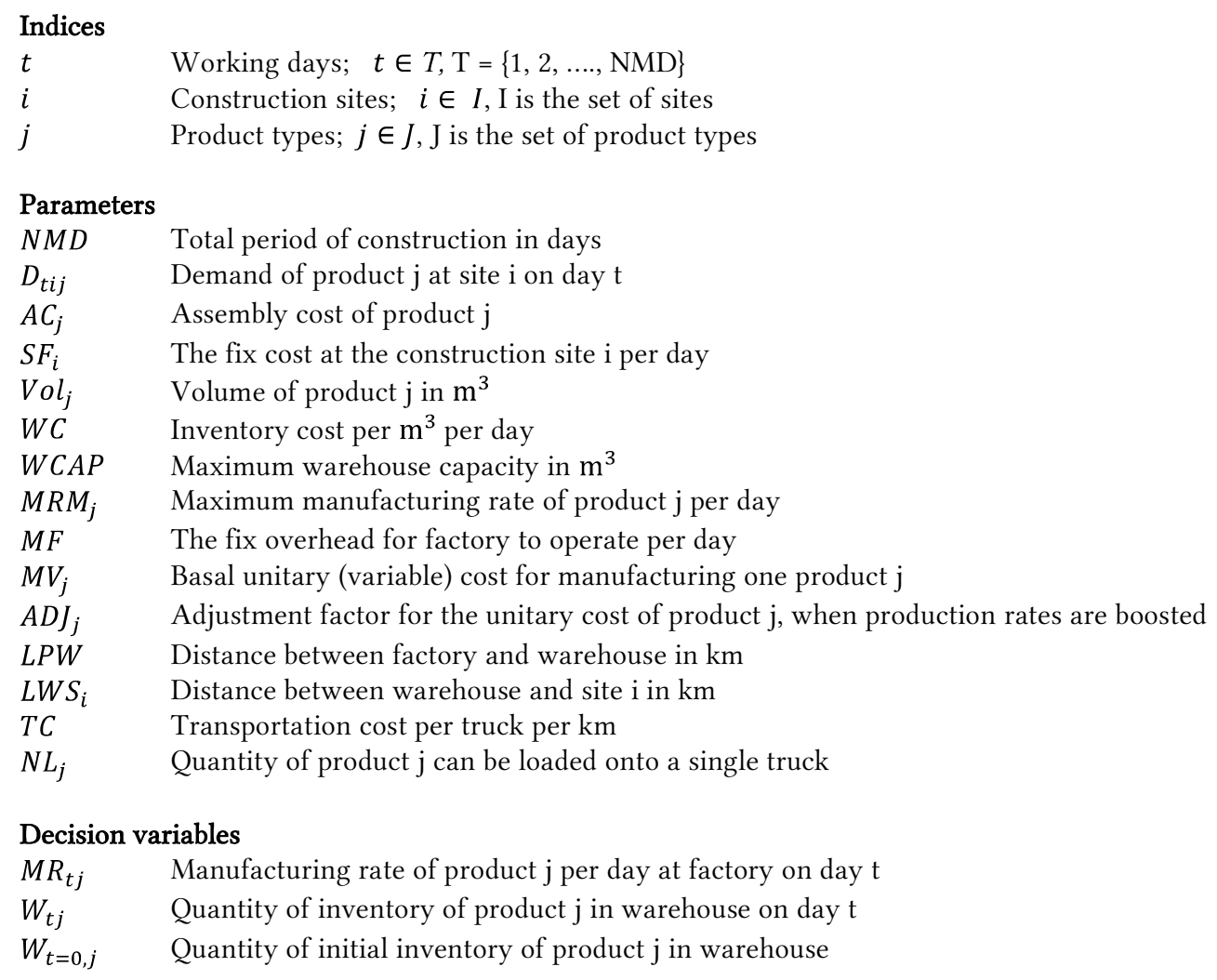




\section{Objective function:}

$$
\begin{aligned}
& \text { Minimize: } T O C=F P C+V P C+I C+T C A+S C A \\
& F P C=M F \cdot N M D+M F \cdot M a x\left(\frac{W_{0 j}}{M R M_{j} / 2}\right) \\
& V P C=\sum_{t \in T} \sum_{j \in J} M R_{t j} \cdot M V_{j} \cdot\left[1+A D J_{j} \cdot\left(\frac{M R_{t j}}{M R M_{j}}\right)\right]+\sum_{j \in J} W_{0 j} \cdot M V_{j} \cdot\left[1+A D J_{j} \cdot \frac{1}{2}\right] \\
& I C=\sum_{t=0}^{N M D} \sum_{j \in J} W_{t j} \cdot V o l_{j} \cdot W C \\
& T C A=\sum_{t \in T} \sum_{j \in J} \frac{M R_{t j}}{N L_{j}} \cdot T C \cdot L P W+\sum_{t \in T} \sum_{i \in I} \sum_{j \in J} \frac{D_{t i j}}{N L_{j}} \cdot T C \cdot L W S_{i}+\sum_{j \in J} \frac{W_{0 j}}{N L_{j}} \cdot T C \cdot L P W \\
& S C A=\sum_{i \in I} S F_{i} \cdot N M D+\sum_{j \in J} \sum_{t \in T} \sum_{i \in I} D_{t i j} \cdot A C_{j}
\end{aligned}
$$

The objective is to minimise the total operational cost (TOC) in Equation (1), which is composed by various costs. Equations (1.1) and (1.2) calculate the fixed and variable production costs for producing all types of products, respectively. The cost for manufacturing the initial inventory is also considered in the second terms of the respective equations. Note that the initial inventory is assumed to be produced at the half maximum production rate. Equation (1.3) calculates the inventory cost at the warehouse. Equation (1.4) calculates the transportation cost for moving products from the factory to the warehouse, from the warehouse to all the construction sites, and for moving the initial inventory from the factory to the warehouse, in the three terms, respectively. Equation (1.5) calculates the site fix cost and the assembly cost for assembling all types of products on all sites.

\section{Subject to:}

$$
\begin{aligned}
& 0 \leq M R_{t j} \leq M R M_{j} \quad \forall t \in T, \forall j \in J \\
& \sum_{j \in J} W_{t j} \cdot V l_{j} \leq W C A P \quad \forall t \in 0 \text { to } N M D \\
& \sum_{t \in T} M R_{t j}+W_{0 j}=\sum_{t \in T} \sum_{i \in I} D_{t i j} \quad \forall j \in J \\
& W_{t j}=W_{t-1, j}+M R_{t j}-\sum_{i \in I} D_{t i j} \quad \forall t \in T, \forall j \in J \\
& W_{t-1, j}+M R_{t j} \geq \sum_{i \in I} D_{t i j} \quad \forall t \in T, \forall j \in J
\end{aligned}
$$

Constraint (2) states that the manufacturing rate of each type of product is within a predefined range. Constraint (3) ensures that the inventory volume sum for all products is smaller than the warehouse capacity. Constraint (4) makes sure that the production of modular products follows the demand on the sites. Constraint (5) represents the balance of inventory. Constraint (6) stands for the non-negativity of inventory. 


\section{Case study: bathroom pods a modular building project}

The model has been tested on a case study involving delivery of bathroom pods to a new hospital project in Scotland. The case study implements a three-tier logistic structure in which two types of bathroom pods are manufactured, temporarily stored, and assembled on the three construction sites. The project duration was 2 years, and comprised assembly of bathroom pods for 344 single rooms.

\section{RESULTS}

Using a bathroom pod case study, this section presents a model which determines the most favourable production scheme and initial inventory level needed to serve multiconstruction sites under two demand profiles, namely demand affected by foreseeable and abrupt disruptions. To deal with these demand profiles, two versions of the model instance have been developed using MILP and the models were implemented in IBM ILOG CPLEX Studio (version 12.6).

\section{Dealing with foreseeable disruptions}

According to previous studies (Assaf and Al-Hejji 2006; Gündüz et al. 2013; Nadu 2014), the most commonly recognised type of foreseeable disruption is inclement weather. Nowadays weather forecasts are quite accurate and easy to obtain. In addition, meteorological information such as the probability of precipitation and wind conditions can be readily transformed into variations in the demand level for building materials using mathematical equations. (Li et al. 2013; Jung et al. 2016).

For demonstration purpose, 20 scenarios of how the assembly of modular components will proceed over a 4-day period (June 24-27, 2016 in London area) with their probability of occurrence are derived from the daily weather forecast data for rain and wind conditions. Table 1 shows part of the 20 scenarios for the two module types studied, i.e. type- $\mathrm{A}$ and type-B bathroom pod. Here we assume that 8 type-A pods and 6 type-B pods are assembled in each of the three construction sites. In total, 24 type-A and 18 type-B bathroom pods are assembled.

Table 1: Foreseeable disrupted scenarios.

\begin{tabular}{cccccccccccc}
\hline Date & \multicolumn{2}{c}{ June 24 } & \multicolumn{2}{c}{ June 25 } & \multicolumn{2}{c}{ June 26 } & \multicolumn{2}{c}{ June 27 } & \multicolumn{2}{c}{ Total } & \\
\cline { 1 - 7 } Pod type & A & B & A & B & A & B & A & B & A & B & Prob. \\
\hline Scenario 1 & 4 & 3 & 3 & 2 & 1 & 1 & 0 & 0 & 8 & 6 & $28.18 \%$ \\
Scenario 2 & 4 & 3 & 3 & 1 & 1 & 2 & 0 & 0 & 8 & 6 & $15.17 \%$ \\
$:$ & $:$ & $:$ & $:$ & $:$ & $:$ & $:$ & $:$ & $:$ & $:$ & $:$ & $:$ \\
Scenario 20 & 3 & 2 & 2 & 1 & 3 & 2 & 0 & 1 & 8 & 6 & $0.05 \%$ \\
\hline
\end{tabular}

The outputs of the model are shown in Table 2 . The model initially calculates the expected demand of both pod types per day (see row 3 ). Then it generates the most favourable initial inventory level (row 5 - June 23) and daily production rate for the whole duration (row 4, June 24-27). Note that the costs for manufacturing and transportation of the initial inventory have been considered. In addition, the model reveals the variation of daily inventory (row 5, June 24-27). 
Table 2: Output for the foreseeable disruption scenarios

\begin{tabular}{ccccccccccc}
\hline Date & \multicolumn{2}{c}{ June 23 } & \multicolumn{2}{c}{ June 24 } & \multicolumn{2}{c}{ June 25 } & \multicolumn{2}{c}{ June 26 } & \multicolumn{2}{c}{ June 27 } \\
\hline Pod type & A & B & A & B & A & B & A & B & A & B \\
\hline Expected demand & -- & -- & 11 & 8 & 8 & 5 & 5 & 5 & 0 & 0 \\
Production rate & -- & -- & 6 & 4 & 7 & 4 & 5 & 4 & 0 & 0 \\
Inventory level & 6 & 6 & 1 & 2 & 0 & 1 & 0 & 0 & 0 & 0 \\
\hline
\end{tabular}

\section{Dealing with abrupt disruptions}

An alternative model formulation was developed to address abrupt changes in the demand on sites. Here abrupt disruptions refer to unexpected events, which have negative consequences on the original construction schedule.

To demonstrate an abrupt disruption, we assumed a scenario in which a strong wind appears unexpectedly on day 2 of construction, and there is no sign of stopping over the next few days. The assembly rate drops to one half of its original value. The demand and the outputs of the model for the original scenario and the new scenario (disrupted) are shown in Table 3 . Here we assume that originally 4 type-A and 4 type-B bathroom pods are assembled in each of the three construction sites per day. In total, 36 type-A and 36 type-B bathroom pods are assembled in three days (see row 4). The best initial inventory and production rate for the original scenario are also shown in rows 5 and 6, respectively.

The disrupted demand profile is shown in row 8 (day 2-5). Since the strong wind happens abruptly on day 2 , the factory does not have enough changeover time to adopt a new production rate until day 3 . The program thus sticks to the original production rate on day 2 and then calculates the optimal production rates for day 3 and beyond. The inventory level and production rate to generate the lowest total cost in the new scenario are given in rows 9 and 10 (day 3-5).

Table 3: Demand and output for the original and abrupt disrupted scenario

\begin{tabular}{|c|c|c|c|c|c|c|c|c|c|c|c|c|}
\hline Day & & & & & & & & & & & & \\
\hline \multicolumn{13}{|c|}{ Original Scenario (no-delay) } \\
\hline Pod type & A & B & A & $\mathrm{B}$ & A & $\mathrm{B}$ & A & $\mathrm{B}$ & A & $\mathrm{B}$ & A & B \\
\hline Demand & -- & -- & 12 & 12 & 12 & 12 & 12 & 12 & -- & -- & -- & -- \\
\hline Production rate & -- & -- & 6 & 6 & 6 & 6 & 6 & 6 & -- & -- & -- & -- \\
\hline Inventory level & 18 & 18 & 12 & 12 & 6 & 6 & 0 & 0 & -- & -- & -- & -- \\
\hline \multicolumn{13}{|c|}{ New Scenario (abrupt disrupted) } \\
\hline Demand & -- & -- & 12 & 12 & 6 & 6 & 6 & 6 & 6 & 6 & 6 & 6 \\
\hline Production rate & -- & -- & 6 & 6 & 6 & 6 & 2 & 2 & 2 & 2 & 2 & 2 \\
\hline Inventory level & 18 & 18 & 12 & 12 & 12 & 12 & 8 & 8 & 4 & 4 & 0 & 0 \\
\hline
\end{tabular}




\section{General discussion}

This research proposed a model to output optimal logistics configurations specifically with modular construction in mind. The model incorporates several special features of modular construction. The modular products employed are generally made to order and designed exclusively to be used in a single project. This can lead to two main consequences. First, each type of module is manufactured in a quantity that matches exactly the need of the corresponding construction project, and the inventory should reach zero at the end of its assembly. Second, when the production of a module falls behind the demand, there is no way to source the module from the market. To solve this problem, this study takes the approach of building up an appropriate level of initial inventory. Here, an appropriate level means that the demand can be met under all possible scenarios, and the total cost is minimised. These characteristics distinguish our model from those developed to be used for general merchandise and traditional construction supply chains.

Furthermore, compared to the materials used for conventional construction projects, modular products are large in size. As a result, manufacturing factories and construction sites typically do not have enough space to store them. This issue is exacerbated when construction sites are located in urban settings. To solve this issue, this study adds a warehouse into the logistic system. Ideally, modular products are immediately transported from the factory to the warehouse once completed, and they are sent to the construction sites daily in response to the demand. Our model can also estimate the maximum level of inventory during the whole period of construction, providing useful information to determine the most suitable size for the warehouse.

We have developed two versions of the model instance to deal with two demand profiles. The first version is to address foreseeable demand variations in construction sites. In this study, the weather factor is used as an example. Weather is a widely accepted delay factor in construction and modern technology makes its prediction quiet accurate. Our model can help a factory set up the best weekly production plan based on a weekly weather forecast. This can be a very practical application.

The second version of the model is to deal with abrupt demand variations on sites. Accidents inevitably happen, and a logistic system must be able to respond and find the best solution in the shortest time. Our model imitates the real situation, in which the production plan is not changed until the very next day after the disruption, due to insufficient changeover time in the factory. The model thus can be of great help to managers whose responsibility is to make decisions for production planning in a short time frame.

\section{CONCLUSION}

The three-tier logistics structure investigated in this research is absent in stick-built construction projects. The most favourable responses in the manufacturing factory and the storage facility following demand variations at construction sites have never been studied. The model established in this research, which finds the optimal configurations for the supply chain of modular construction, can serve as a basis for decision making.

Future work will add more features to the model, such as determining the number and location of warehouses and admitting uncertainty in transportation. The model can be tested with a larger variety of disruptions, and validated with more complete and detailed data from relevant construction projects. 


\section{ACKNOWLEDGEMENTS}

The authors acknowledge the support of Laing O’Rourke and the Top University Strategic Alliance (TUSA) PhD scholarships for students from Taiwan.

\section{REFERENCES}

Akkermanns, H.A., Bogerd, P., and Vos, G.C.J.M. (1999). Virtuous and vicious cycles on the road towards international supply chain management. Int. J. Oper. Prod. Man., 19(5), pp. 565-581.

Adulyasak, Y., and Jaillet, P. (2015). Models and algorithms for stochastic and robust vehicle routing with deadlines. Transport. Sci., 50(2), pp. 608-626.

Assaf, S. A., and Al-Hejji, S. (2006). Causes of delay in large construction projects. Int. J. Proj. Manag., 24(4), pp. 349.

Azhar, S., Lukkad, M.Y., and Ahmad, I. (2013). An investigation of critical factors and constraints for selecting modular construction over conventional stick-built technique. Int. J. Constr. Educ. Res., 9(3), pp. 203-225.

Chandra, P., and Fisher, M. L. (1994). Coordination of production and distribution planning. Eur. J. Oper. Res., 72(3), pp. 503-517.

Coelho, L. C., and Laporte, G. (2014). Optimal joint replenishment, delivery and inventory management policies for perishable products. Comput. Oper. Res., 47, pp. 42-52.

De La Torre, M.L. (1994). A review and analysis of modular construction practice. MS Diss., Civil Engineering, Lehigh University, Bethlehem, PA, USA.

Díaz-Madroñero, M., Peidro, D., and Mula, J. (2015). A review of tactical optimization models for integrated production and transport routing planning decisions. Comput. Ind. Eng., 88, pp. 518-535.

Gündüz, M., Nielsen, Y., and Özdemir, M. (2013). Quantification of delay factors using the relative importance index method for construction projects in Turkey. ASCE J. Manage. Eng., 29(2), pp. 133-139.

Lawson, M., Ogden, R., and Goodier, C. (2014). Introduction to planning of modular buildings. Lawson, M. (Ed.). Design in modular construction. CRC Press, Boca Raton, FL, USA.

Li, H. X., Al-Hussein, M., Lei, Z., and Ajweh, Z. (2013). Risk identification and assessment of modular construction utilizing fuzzy analytic hierarchy process (AHP) and simulation. Can. J. Civil Eng., 40(12), pp. 1184-1195.

Li, Z., Shen, G.Q., and Xue, X. (2014). Critical review of the research on the management of prefabricated construction. Habitat Int., 43, pp. 240-249.

Nadu, T. (2014). Study on the quantification of delay factors in construction industry. Int. J. Emerg. Technol. Adv. Eng., 4(1), pp. 105-113.

Rogers, G.G., and Bottaci, L. (1997). Modular production systems: A new manufacturing paradigm, J. Intell. Manuf., 8(2) pp. 147-156.

Sambasivan, M., and Soon, Y. W. (2007). Causes and effects of delays in Malaysian construction industry. Int. J. Proj. Manag., 25(5), pp. 517-526.

Sweis, G., Sweis, R., Hammad, A. A., and Shboul, A. (2008). Delays in construction projects: The case of Jordan. Int. J. Proj. Manag., 26(6), pp. 665-674. 